
\title{
28 Research Square \\ QTL mapping of root traits in wheat under different phosphorus levels using hydroponic culture
}

\section{Mengjiao Yang}

Institute of Crop Sceience,CAAS

\section{Cairong Wang}

Agricultural Research Institue of Yili

Muhammad Adeel Hassan

Institute of Crop Science,CAAS

\section{Faji Li}

Institute of Crop Science,CAAS

Xianchun Xia

Institute of Crop Science,CAAS

\section{Shubing Shi}

College of Agronomy,Xinjiang Agricultural University

Yonggui Xiao ( $\nabla$ xiaoyonggui@caas.cn )

Institute of Crop Science,CAAS https://orcid.org/0000-0002-9011-222X

Zhonghu He

Institute of Crop Science,CAAS

\section{Research article}

Keywords: Genome-wide linkage mapping, Quantitative trait loci, Root traits, SNP array

Posted Date: December 22nd, 2020

DOI: https://doi.org/10.21203/rs.2.13411/v3

License: @ (i) This work is licensed under a Creative Commons Attribution 4.0 International License. Read Full License

Version of Record: A version of this preprint was published at BMC Genomics on March 11th, 2021. See the published version at https://doi.org/10.1186/s12864-021-07425-4. 


\section{Abstract}

Background: Phosphorus $(\mathrm{P})$ is an important in ensuring plant morphogenesis and grain quality, therefore an efficient root system is crucial for P-uptake. Identification of useful loci for root morphological and P uptake related traits at seedling stage is important for wheat breeding. The aims of this study were to evaluate phenotypic diversity of Yangmai 16/Zhongmai 895 derived doubled haploid (DH) population for root system architecture (RSA) and biomass related traits (RBT) in different $\mathrm{P}$ treatments at seedling stage using hydroponic culture, and to identify QTL using 660K SNP array based high-density genetic map.

Results: All traits showed significant variations among the $\mathrm{DH}$ lines with high heritabilities ( 0.76 to 0.91$)$ and high correlations ( $r=0.59$ to 0.98 ) among all traits. Inclusive composite interval mapping (ICIM) identified 34 QTL with $4.64-20.41 \%$ of the phenotypic variances individually, and the log of odds (LOD) values ranging from 2.59 to 10.43. Seven QTL clusters (C1 to C7) were mapped on chromosomes 3DL, 4BS, 4DS, 6BL, 7AS, 7AL and 7BL, cluster C5 on chromosome 7AS (AX-109955164 - AX-109445593) with pleiotropic effect played key role in modulating root length (RL), root tips number (RTN) and root surface area (ROSA) under low $P$ condition, with the favorable allele from Zhongmai 895.

Conclusions: This study carried out an imaging pipeline-based rapid phenotyping of RSA and RBT traits in hydroponic culture. It is an efficient approach for screening of large populations under different nutrient conditions. Four QTL on chromosomes 6BL (2) and 7AL (2) identified in low P treatment showed positive additive effects contributed by Zhongmai 895 , indicating that Zhongmai 895 could be used as parent for Pdeficient breeding. The most stable QTL QRRS.caas-4DS for ratio of root to shoot dry weight (RRS) harbored the stable genetic region with high phenotypic effect, and QTL clusters on 7A might be used for speedy selection of genotypes for P-uptake. SNPs closely linked to QTLs and clusters could be used to improve nutrient-use efficiency.

\section{Background}

Phosphorus $(P)$ is an important macro-element for ensuring plant development, productivity, and grain quality [1]. P deficiency causes abnormal physiological and biochemical metabolism during critical plant growth stages and resulted yield losses [2]. P as phosphate is immobile in most of the soil types that make its application on the soil surface less beneficial for plants. While efficient uptake of $P$ from deep soil depends on plant's underground organs [3]. In crops, an efficient root system is crucial for P-uptake. For example, increase in root to shoot ratio in most of the elite cultivars helps to up-take P from deep soil or by growing longer root hairs to exploit the spatial characteristics of soil for maximum nutrient storage in shoots [4,3]. Therefore, optimization of root and biomass related attributes such as root length, root width, root tips number, root diameter, root biomass and shoot biomass at seedling stage could provide a promising avenue to explore early variations correlated with high $\mathrm{P}$ uptake. Genetic diversity for root-related traits under different nutrient conditions has been also considered very important for grain yield enhancement $[5,6]$. Therefore, improvement of nutrient uptake through useful variations in seedling root and biomass traits under varied growth conditions could provide a sustainable solution for developing elite cultivars $[2,7,8]$.

In wheat, QTLs have been detected for root traits under different P treatments across the 21 chromosomes [9, $10]$. But despite the many genetic interactions which have been determined for the seedling biomass and root 
system architecture traits, still few loci were reported with major effects [11, 12]. Accurate phenotyping of root traits under normal field conditions is difficult, whereas traditional methods such as soil columns and soil cores are time-consuming and laborious for screening of large populations $[14,15]$. Artificial systems like sand, germination paper and hydroponic based cultures have been used as proxies for characterization of root traits $[4,16]$. Hydroponic culture with digital imaging has given new opportunities to detect number of root traits with different aspects of root development compared with sand culture and germination paper techniques [11]. Moreover, hydroponic technique can be easily applied for rapid and precise screening of large populations to bridge the phenome to genome knowledge gaps. Several common QTL related to root biomass and root system architecture traits have been reported in both hydroponic and field trials conditions $[11,12,17]$. But, there is no report regarding cloning of QTL for P-uptake related root traits or P uptake efficiency yet.

Nowadays, construction of high-density genetic maps has accelerated the accuracy of quantitative genomic analysis. Therefore, it could increase the chance for identification of true loci for complex traits [13]. The 660K SNP array in wheat has greatly improved the density of genetic maps for QTL analysis compared with the earlier $90 \mathrm{~K}$ array $[18,19]$. In this study, we have used hydroponic culture-based image pipeline for root phenotyping and 660K SNPs array for QTL and joint QTL analysis. This will identify useful loci and can help to understand their pleiotropic effect for multiple root morphological and P-uptake related traits during selection. The aims of this study were (1) to evaluate phenotypic diversity of Yangmai 16/Zhongmai 895 derived doubled haploid (DH) population for seedling root and biomass related traits in different P treatments , (2) to identify QTLs for root traits and biomass at seedling stage under low and high P conditions using 660K SNP array based high-density genetic map and (3).to detect QTL with pleiotropic effect for multiple traits.

\section{Methods}

\section{Plant materials}

The panel of $198 \mathrm{DH}$ lines from the cross of Yangmai 16/Zhongmai 895 were evaluated for root-related traits in hydroponic culture. The female parental Yangmai 16 is a spring wheat cultivar with drought resistance attributes and cover the largest planting area in the middle and lower Yangtze River Region. Zhongmai 895 is a facultative cultivar and widely cultivated in southern parts of the Yellow and Huai Valleys. This has been characterized as high yielding with drought and heat resistance ability, strong roots and early vigor.

\section{Hydroponic culture and experimental design}

Hoagland's nutrient solution was used [20], and three P levels were kept at zero (control), low and high $\mathrm{P}$ contents $\left(\mathrm{KH}_{2} \mathrm{PO}_{4} 0,0.005,0.25 \mathrm{mmol} / \mathrm{L}\right.$, respectively). Whereas, levels of $\mathrm{KCl}$ in solution were at $0.35,0.345$ and $0.10 \mathrm{mmol} / \mathrm{L}$, respectively in the three treatments to maintain a common nutrient concentration across treatments [21] (Table 1). The experiments were conducted in randomized complete blocks (RCBD), with three replications from March 15 to April 28, 2017, and 30 healthy seeds of each DH line were used for each treatment.

The seeds of each DH line were sterilized for $15-20$ minutes in a $10 \% \mathrm{H}_{2} \mathrm{O}_{2}$ solution. After rinsing 5-6 times in sterilized water, seeds were placed on moisturized germination paper in glass Petri dishes, crease-side down and left for 36 hours in darkness to initiate germination. After the early appearance of germination, seeds were 
transferred to sand ( $2 \mathrm{~mm}$ diameter) box in a dark environment for seedling growth at $24^{\circ} \mathrm{C}$ for 72 hours. The sand box was kept under a constant environment room $\left(12 \mathrm{~h}\right.$ photo-period: $16^{\circ} \mathrm{C}$ day and $13^{\circ} \mathrm{C}$ night, light intensity at $400 \mu \mathrm{mol} \mathrm{m} \mathrm{m}^{-2} \mathrm{~s}^{-1}$ PAR and relative humidity at 70\%). Three uniformly sprouted seeds with $\sim 5 \mathrm{~mm}$ in roots length for each replication were transferred to holes in trays (the seedling was holed with a sponge), and were placed on plastic tanks $(660 \times 480 \times 280 \mathrm{~mm})$ containing $20 \mathrm{~L}$ of nutrient solution. The solution was renewed after every three days. After 10 days (two-leaf stage) plants were harvested and placed in $30 \%$ ethanol prior to imagery for phenotyping.

\section{Trait measurements}

Five root system architecture (RSA) traits, viz. root length ( $R L)$, root volume (RV), root diameter (RD), root tip number (RTN), root surface area (ROSA) were captured through images using a scanner (Perfection V700/V750 2.80A; Epson, China). Images were analyzed by using a software RootNav V1.7.5, which was operationally semiautomated [22]. Root biomass-related traits (RBT), including shoot dry weight (SDW) and root dry weight (RDW) were measured after oven-drying for $72 \mathrm{~h}$ at $70^{\circ} \mathrm{C}$ (mg/plant). Total dry weight (TDW) was estimated as the sum of SDW and RDW, and ratio of root to shoot dry weight (RRS) was measured as ratio between RDW and SDW.

\section{SNP genotyping and QTL analysis}

The DH lines and parent cultivars were genotyped through Wheat 660K SNP array synthesized by Affymetrix and commercially available from Capital Bio Corporation (Beijing, China; http://www.capitalbio.com). Genetic map was contacted by Wang et al. [23] from our lab. Briefly, markers with no polymorphisms between parents, severely distorted segregations, and missing rate greater than $20 \%$ were removed in the subsequent linkage analysis. Finally, 10,242 markers each representing a bin site were selected to construct the linkage map of Yangmai 16/Zhongmai 895 population., Map was comprised 25 linkage groups, covering all 21 wheat chromosomes. Among them, chromosomes 1B, 2B, 4A and 7A consisted of two linkage groups, and the remaining chromosomes were with only one linkage group. Inclusive composite-interval mapping was used for QTL analysis in IciMappingV4.1 software [24], and averaged data from the three replicates were used for QTL detection. The SNP genotypes of Yangmai 16 were defined as A, and those of Zhongmai 895 as B. Alleles from Yangmai 16 reduced trait values when the additive effects were negative. Kosambi mapping approach was used to convert recombinant frequencies into distance map [25]. Locations of QTLs for the root traits were detected by inclusive composite interval mapping-additive (ICIM-ADD) by using same software as for the QTL analysis. The threshold for significant QTL of each trait was demarcated by 1000-permutations at $P=0.05$ [26], and minimum LOD score at 2.5 with walking speed at $1.0 \mathrm{cM}$. Joint QTL analysis for closely linked pleiotropic QTL was performed using the general linear model scripted in Im package of R software. Phenotypic variance explained by each QTL was calculated as demonstrated in Li et al. [27].

\section{Identification of putative candidate genes}

The genes located in the physical intervals of RSA and RBT-associated genomic regions were screened based on the annotations in the wheat reference genome (CS RefSeq v1.0; IWGSC 2018), and those related to growth, development and nutrient mobilization were considered as candidate genes. Gene annotation was retrieved using EnsemblPlant and EMBL-EBI (http://www.ebi.ac.uk/interpro) databases. Gene annotation for putative proteins was performed using BLAST2GO (https://www.blast2go.com/). 


\section{Statistical analysis}

Pearson's correlations analysis among the traits were estimated using averaged data from each replicate. Significance of variances among DH lines, treatments and interactions between genotypes and treatments $(\mathrm{G} \times \mathrm{T})$ was calculated using following mixed linear model and considered significant at $P<0.05$.

$Y=X \beta+Z \mu+g \mathrm{e}+\varepsilon$

where $Y$ is demonstrated as the response from fixed $(\beta)$ and random $(\mu)$ effects with random error $(\varepsilon)$, ge is the genotype $\times$ environment effect while $X$ and $Z$ illustrate fixed and random effects, respectively. Broad sense heritabilities for all traits were estimated using genotypes as a random effect following [28].

$h^{2}=\sigma_{g}^{2} /\left(\sigma_{g}^{2}+\sigma_{g t}^{2} / r+\sigma_{\varepsilon}^{2} / \mathrm{rt}\right)$

where $\sigma_{g}{ }^{2}, \sigma_{g t}{ }^{2}$ and $\sigma_{\varepsilon}{ }^{2}$ represent genotype, genotype (DH line) $\times \mathrm{P}$ treatment interaction and error variances, respectively, while $t$ is indicated $P$ treatments and $r$ is replicates. The $R$ package was used for all statistical analyses [29].

\section{Results}

\section{Phenotypic variation and correlations among traits under $\mathrm{P}$ treatments}

Data for all nine traits were normally distributed across the three P treatments (Fig. S1). Under low P condition, Zhongmai 895 showed higher RL, RV, ROSA, RDW, TDW and RRS, but lower RD, RTN, and SDW than Yangmai 16. Except for RD and RRS in the high P treatment, Yangmai 16 had higher RL, RV, RTN, ROSA, SDW, RDW and TDW than Zhongmai 895 (Fig. 1).

Phenotypic variances among the DH lines were significant $(P<0.0001)$. Transgressive segregations across $\mathrm{P}$ treatments were observed for most of traits (Fig. 1; Table 2). The average values of the DH lines for RL, RV, RTN, and RRS were higher than parents in the low $\mathrm{P}$ treatment, indicating positive effects for root vigor from both parents (Fig. 1 and 2). Broad sense heritabilities of nine traits were high ranged from 0.76 to 0.91 (Table 2).

RSA and RBT traits were correlated significantly ( $r=0.59$ to 0.98 at all three P levels) with each other. However, RD was negatively correlated with RL, RTN and ROSA ( $r=-0.23$ to -0.69$)$ (Fig. 3).

\section{QTL for root system architecture traits}

Nineteen QTL from the three P treatments were identified for RSA traits i.e. RL, RV, RTN and ROSA on chromosomes 1BL, 2BL, 2DL, 3DL, 4BS, 6AL, 6BL (2), 6DS, 7AS (5), 7AL (3) and 7BL (2) (Table 3). Among them 6 QTL were detected for the zero control, and 7 in the low and 6 in the high $P$ treatments with the phenotypic variances explained of $45.1,48.0,53.7 \%$, respectively. Seventeen QTL on chromosomes 2BL, 2DL, 3DL (2), 4BS (3), 6AL, 6BL (3), 6DS (2), 7AS (2), 7AL (2) conferred positive additive effects contributed by Zhongmai 895 (Table 3). In the low P treatment, three QTL were identified for each of RL and RTN, explaining $20.7 \%$ and $21.7 \%$ of phenotypic variances, respectively. RL and RTN were co-located on chromosomes 6BL, 7AL and 7BL. Zhongmai 895 possessed the positive alleles on 6BL and 7AL for increased phenotypic values (Table 3). 


\section{QTL for root biomass-related traits}

Fifteen QTL for RBT traits were identified on chromosomes 3AS (3), 3DL, 4BS (5), 4DS (4), 6BL and 6DS (Table 3). Two, 4 and 9 QTL were identified in the zero, low and high $P$ treatments, and explained $34.0,42.8$ and $67.6 \%$ of the phenotypic variances, respectively. A stable QTL (QRDW.caas-4BS) was identified under both low and high P conditions, explaining 8.1 to $17.7 \%$ of the phenotypic variances for RDW. A pleiotropic QTL on chromosome 4DS in interval $A X-109816583$ - $A X-109478820(16.64-30.66 \mathrm{Mb})$ detected in the low P treatment for RDW co-located with 3 QTL in all three P treatments for RRS explained 7.1 to $20.4 \%$ of the phenotypic variances (Table 3 ).

\section{QTL clusters}

Fifteen QTL were grouped in seven clusters (C1 to C7) for both RSA and RBT traits in all three P treatments. These clusters were identified in the same or close marker intervals (Fig. 4). Genetic regions of these clusters were located on 3DL, 4BS, 4DS, 6BL, 7AS, 7AL and 7BS chromosomes, respectively. Of these, $\mathrm{C} 1$ was on 3DL for SDW and RTN under high P treatment. C2 for RV and RRS on 4BS was detected in a $0.31 \mathrm{Mb}$ interval between SNPs $A X-109491270(21.79 \mathrm{Mb})$ and $A X-108815849$ (21.42 Mb). C3 on 4DS comprised QTL for RDW and RRS. QTL in clusters on 4B (16.64 - 30.66 Mb) and 4D (32.42 - 37.86 Mb) were at or very near to reduced plant height gene loci $R h t-B 1(30.8 \mathrm{Mb})$ and $R h t-D 1(18.9 \mathrm{Mb})$, respectively. C4, C6 and C7 involved the same traits (RL and RTN) on chromosomes 6BL, 7AL and 7BL. C5 on 7AS (AX-109955164-AX-109445593) affected RL, RTN and ROSA, with the favorable allele contributed by Zhongmai 895 (Fig. 4).Joint QTL analysis reveal that, QTLS presented in four clusters. i.e. C3 (RDW and RRS), C4 (RL and RTN), C5 (RL, RTN, ROSA) and C7 (RL and RTN) were identified as pleiotropic QTL under different P levels (Fig. 4 and Table 4).

\section{Discussion}

\section{Significant variations and correlations observed for RSA and RBT}

Hydroponic-based rapid phenotyping approach was used to measure for RBT and RSA related traits in DH population. Previous studies identified strong correlations between such laboratory-based experiments and field data [30,31]. Therefore, use of digital dataset on RBT and RSA can be used to explore phenotypic variations among the $\mathrm{DH}$ population under varied nutrient levels. Most of the phenotypes were higher under the high $\mathrm{P}$ treatment compared with zero and low $\mathrm{P}$ treatments (Fig. 2). High heritabilities and significant genetic variances for root system architecture and biomass traits indicated that these traits could be used as primary selection criteria for enhancement of $P$ uptake and to identify underlying genetics $[12,13]$ (Table 2). The present results corroborated earlier findings for genetic variances of root-related traits under different nutrient treatments $[6,32$, 33].

$P$ deprivation restricts the growth of main roots, while increases the lateral roots elongation with high numbers of root hairs [34]. This phenomenon leads higher ratio of root to shoot that significantly changes the root architecture for greater nutrient up-take [10]. In this study, RSA traits i.e. RL, RV, RTN and ROSA, and RBT traits i.e. RDW and RRS showed higher growth and highly positive correlation between each other at the low $\mathrm{P}$ level (Fig. 2,3). This trend was contributed by Zhongmai 895, which also had longer roots, high root tip number and high RRS in the low $\mathrm{P}$ treatment. High accumulation of SDW under high P conditions and greater RRS under low 
P were observed in Yangmai 16 (Fig. 1). Zhongmai 895 performed higher as compared to Yangmai 16 across the $\mathrm{P}$ treatments, as previously reported elite for high root growth at seedling stage and field-based nitrogen use efficiency [35, 36]. SDW and RRS were negatively correlated across treatments (Fig. 3), although previous work found that low $P$ led to reduced root biomass and had a significant impact on root system architecture traits [4, $13,37]$. A significantly negative correlations ranging from -0.23 to -0.69 of RD with RL, RTN and ROSA in all three $\mathrm{P}$ treatments indicated a negative association of RD with high $\mathrm{P}$ uptake among DH lines (Fig. 3). A similar trend also observed for Zhongmai 895 under high $\mathrm{P}$ treatment (Fig. 1). These kind of variations among the population for complex root behavior could be important for genetic dissection of useful loci.

\section{QTL identified under phosphorus treatments}

Significant variances among genotypes allowed to explore genomic regions associated with the observed traits [4]. Several QTL were identified previously using hydroponic culture, which showed a vital role in nutrient uptake and a positive correlation with yield-related morphological traits. Here we identified $34 \mathrm{QTL}$ on 1B, 2B, 2D, 3A, 3D, 4B, 4D, 6A, 6B, 6D, 7A and 7B chromosomes across the $P$ treatments (Table 3). Some QTL were already reported for root system architecture and root biomass-related traits $[12,38]$. New loci closely linked with $A X-109273188$ (16.63 Mb) on 3AS, AX-10934618 (18.67 Mb) on 6DS, AX-109955164 (116.62 Mb) on 7AS , AX-109109966788 (725.54 Mb) on 7AL and $A X-109289805(705.84 \mathrm{Mb})$ on 7BL showed significant influence for root growth under low P-condition.

The genetic diversity for root vigor under low $\mathrm{P}$ conditions could potentially improve $\mathrm{P}$ acquisition efficiency and described some QTL for RBT under low P conditions [11]. We also detected QTL on 2BL, 4BS, 4DS, 6BL, 7AL and 7BL showing high phenotypic variances for RSA traits i.e. RTN, RRS and RL under low P. (Table 2). Previously, Su et al. $[9,37]$ evaluated two DH populations in pot and field experiments and reported a common QTL on chromosome 4B associated with shoot biomass and tiller number, was potentially important for $\mathrm{P}$ efficiency. Here, QTL in same genomic region of the 4B chromosome were detected for RDW and RRS (Table 3). This QTL was nearly co-located with $R h t$ genes for plant height. The Rht-1 locus on 4B, which was a major factor against lodging as part of the green revolution. Interactions between root-related growth traits and $R h t$ genes were reported as important in early vigor and nutrient uptake [11, 39, 40,41]. These reports had demonstrated contrasting impact of $R$ ht genes on seedling traits under different nutrient conditions as compare to our findings. In our results, both QTL mapped on 4B (16.64-30.66 Mb) and 4D (32.42-37.86 Mb) in low P corresponding to $R h t-B 1 b(30.9 \mathrm{Mb})$ and $R h t-D 1 b(18.9 \mathrm{Mb})$, respectively, had negative impact on RRS among DH lines in contrast with a previous report [40].

QTL on 2DL and 6BL for RTN, RL and SDW under low P condition were likely to be those which were demonstrated for root related traits under $P$ sufficiency in pot trials [37] and hydroponic culture [4]. Therefore, identification of those QTL influencing root traits for high nutrient uptake under varied conditions could be important for genotypic selection. RL, RTN and ROSA are important traits for nutrient uptake and early seedling vigor. Five QTL on chromosome 7A explained higher phenotypic variances of 4.6 to $11.9 \%$ for RL, RTN and ROSA. Four of these QTL detected under high P conditions and negatively influenced the root elongation, RTN and ROSA. Whereas, the QTL on 7AL controlling RTN had a positive role by increasing RTN in low P condition (Table 3). This QTL could play a vital for future crop breeding to improve the P-uptake. Closely linked QTL 
QRL.caas-7BL and QRTN.caas-7BL near AX-109289805(705.84 Mb) could also be important for early vigor under $\mathrm{P}$ deficient conditions, whereas their strong relationship with kernel number per spike was earlier demonstrated by Zhang et al. [42]. SNPs linked with QTL for these traits on 7A and 7B stably detected in different nutrient conditions might be of great value for wheat breeding.

\section{Putative candidate genes}

Putative candidate genes for new QTL identified on 3AS for SDW, RDW and TDW was linked with E3-Ubiquitin ligase gene (TraesCS3A01G030100 14Kb) (Table 5). It had been reported that E3 ubiquitin ligases are involved in lateral root development in monocots and dicots through regulating plant phytohormone biosynthesis, transport and signaling pathways or cell cycle progression. Whereas, Ubiquitin-mediated proteolysis also has a pivotal role in root development, flowering time control and hypocotyl elongation [43]. Based on putative analysis, flanking sequence of SNP linked with QTL on 7AS identified for RL, RTN and ROSA was associated with gene for $\mathrm{Gb}$ protein. Previous reports had shown significant role of Gb protein in stress tolerance and plant growth [44]. Furthermore, a gene for transmembrane domain containing protein family was associated with QTL on 7BL for RL and RTN. These genes have been reported for nutrient import through cell membrane, stress tolerance and vegetative growth in Arabidopsis [45]. These QTL could play an important role for high uptake of $\mathrm{P}$ through alteration in root traits under varied $\mathrm{P}$ conditions.

\section{QTL clusters}

Previously high-density physical mapping results demonstrated about $85 \%$ of gene expression and also has many cluster distributions in wheat genome that covered 5 to $10 \%$ of chromosome regions [46]. In wheat, many QTL clusters were reported in several studies [47-51]. In the present study, seven clusters were identified in three different P treatments (Fig. 4). Clusters C3, C4, C5 and C7 had pleiotropic QTLs for root system architecture and biomass-related traits under different P treatments, whereas QTLs in other clusters contained closely linked multiple genes without pleiotropic effects. Clusters C2 and C3 on chromosomes 4BS and 4DS were linked with reduced plant height genes. Cluster C4 on 6BL had QTLs controlling RL and RTN and previously were reported for thousand grain weight [13]. Cluster C5 on chromosome 7AS (AX-109955164 - AX-109445593) affecting RL, RTN and ROSA was identified for the first time in the present study and SNP linked with this cluster can be used for future wheat improvement. Whereas cluster C7 on chromosome 7BL containing QTLs for RL and RTN was reported for RL and SDW under P-deficient condition. Similar QTL were also identified on 7B chromosome in previous studies [4, 13], but it is not confirmed that QTL in our results are new or co-localization with previously identified loci. (Fig. 4). These results also indicated that QTL identified at seedling stage could be reliable for the selection of yield-related traits measured at maturity [12]. The SNPs tightly linked to QTLs or QTL clusters identified in the present study can be converted to KASP assays and effectively used for MAS to improve nutrient-use efficiency in wheat breeding.

\section{Conclusions}

Thirty-four QTL with significant phenotypic variations for root system architecture and biomass-related traits were identified using high-density genetic map constructed from 660k SNP array and cost-effective hydroponicbased phenotyping pipeline. Four QTLs on chromosomes 6BL (2) and 7AL (2) identified in low P treatment with positive additive effects from Zhongmai 895, indicating that it could be used as parent for P-deficient breeding. 
A stable QTL QRRS.caas-4DS (16.64-30.66 Mb) was also detected across the three P levels, accounted for 8.4 to $20.4 \%$ of the phenotypic variances, which could be used for speedy selection of genotypes for P-uptake.

Among the seven QTLs clusters, C5 identified on chromosome 7AS (AX-109955164-AX-109445593) affecting RL, RTN and ROSA could be vital for improving the nutrient use efficiency of roots under high $P$ condition, whereas, C6 on 7AL under low P condition. Identified chromosome regions, particularly the QTL clusters could be used for molecular marker-assisted selection in future breeding.

\section{Abbreviations}

RSA: Root system architecture; RBT: Root biomass-related traits; RL: Root length; RV: Root volume; RD: Root diameter; RTN: Root tip number; ROSA: Root surface area; SDW: Shoot dry weight; RDW: Root dry weight; TDW: Total dry weight; RRS: Ratio of root to shoot dry weight; PUE: Phosphorus use efficiency; DH: Double haploid; QTLs: Quantitative trait loci; LOD: Log-of-odds

\section{Declarations}

\section{Ethics approval and consent to participate}

Not applicable.

\section{Consent to publish}

Not applicable.

\section{Availability of data and materials}

The datasets used in this article will be available on demand.

\section{Competing interests}

The authors declare that they have no competing interests.

\section{Funding}

This research was supported by National Natural Science Foundation of China (31671691), National Key Project (2016YFD0101804, 2016YFD0101802), and National Key Technology R\&D Program of China (2014BAD01B05). The founding played an important role in the data collecting, analyzing and manuscript writing. 


\section{Authors' contributions}

Performed the experiments: MY and CW. Designed and conceived the experiments: SS, XX, YX, ZH. Statistical data analysis: MY, MAH and FL. Wrote the paper: MY and MAH. All authors read and approved the final version of the manuscript.

\section{Acknowledgements}

We are thankful to Dr. R. A. McIntosh at the Plant Breeding Institute, University of Sydney, and Awais Rasheed from CIMMYT China office for reviewing this manuscript.

\section{References}

1. Malhi SS, Vera CL, Brandt SA. Seed yield potential of five wheat species/cultivars without and with phosphorus fertilizer application on a p-deficient soil in northeastern Saskatchewan. Agri Sci. 2015;6:224231.

2. James RA, Weligama C, Verbyla K, Ryan PR, Rebetzke GJ, Rattey A, Richardson AE, Delhaize E. Rhizosheaths on wheat grown in acid soils: phosphorus acquisition efficiency and genetic control. J Exp Bot. 2016;67:3709-3718.

3. Wang W, Ding GD, White PJ, Wang XH, Jin KM, Xu FS, Shi L. Mapping and cloning of quantitative trait loci for phosphorus efficiency in crops: opportunities and challenges. Plant Soil. 2018:1-22.

4. Guo Y, Kong FM, Xu YF, Zhao Y, Liang X, Wang YY, An DG, Li SS. QTL mapping for seedling traits in wheat grown under varying concentrations of N, P and K nutrients. Theor Appl Genet. 2012;124:851-865.

5. Carvalho P, Azam-Ali S, Foulkes MJ. Quantifying relationships between rooting traits and water uptake under drought in Mediterranean barley and durum wheat. J Integr Plant Biol. 2014;56:455-469.

6. Liu Z, Gao K, Shan S, Gu R, Wang Z, Craft EJ, Mi G, Yuan L, Chen F. Comparative analysis of root traits and the associated QTL for maize seedlings grown in paper roll, hydroponics and vermiculite culture system. Front Plant Sci. 2017;8:436.

7. Clárk RB. Plant genotype differences in the uptake, translocation, accumulation, and use of mineral elements required for plant growth. Plant Soil. 1983;72:175-196.

8. Habash DZ, Bernard S, Schondelmaier J, Weyen J, Quarrie SA. The genetics of nitrogen use in hexaploid wheat: N utilisation, development and yield. Theor Appl Genet. 2007;114:403-419.

9. Su JY, Xiao YM, Li M, Liu QY, Li B, Tong YP, Jia JJ, Li ZS. Mapping QTL for phosphorus-deficiency tolerance at wheat seedling stage. Plant Soil. 2006;281:25-36.

10. Ayalew $\mathrm{H}, \mathrm{Ma} X$, Yan G. Screening wheat (Triticum spp.) genotypes for root length under contrasting water regimes: potential sources of variability for drought resistance breeding. J Agron Crop Sci. 2015;201:189194.

11. Ryan PR, Liao M, Delhaize E, Rebetzke GJ, Weligama C, Spielmeyer W, James RA. Early vigour improves phosphate uptake in wheat. J Exp Bot. 2015;66:7089-7100. 
12. Yuan Y, Gao M, Zhang M, Zheng H, Zhou X, Guo Y, Zhao Y, Kong F, Li S. QTL mapping for phosphorus efficiency and morphological traits at seedling and maturity stages in wheat. Front Plant Sci. 2017;8:614.

13. Zhang H, Wang HG. QTL mapping for traits related to P-deficient tolerance using three related RIL populations in wheat. Euphytica. 2015;203:505-520.

14. Bovill WD, Huang CY, McDonald GK. Genetic approaches to enhancing phosphorus-use efficiency (PUE) in crops: challenges and directions. Crop Pasture Sci. 2013;64:179-198.

15. Gong X, McDonald GK. QTL mapping of root traits in phosphorus-deficient soils reveals important genomic regions for improving NDVI and grain yield in barley. Theor Appl Genet. 2017;130:1885-1902.

16. Atkinson JA, Wingen LU, Griffiths M, Pound MP, Gaju O, Foulkes MJ, Le Gouis J, Griffiths S, Bennett MJ, King J, Wells DM. Phenotyping pipeline reveals major seedling root growth QTL in hexaploid wheat. J Exp Bot. 2015;66:2283-2292.

17. Kabir MR, Liu G, Guan P, Wang F, Khan AA, Ni Z, Yao Y, Hu Z, Xin M, Peng H, Sun Q. Mapping QTL associated with root traits using two different populations in wheat (Triticum aestivum L.). Euphytica. 2015;206:175-190.

18. Cui F, Zhang N, Fan X, Zhang W, Zhao C, Yang L, Pan R, Chen M, Han J, Zhao X, Ji J, Tong Y, Zhang H, Jia J, Zhao G, Li M. Utilization of a Wheat 660K SNP array-derived high-density genetic map for high-resolution mapping of a major QTL for kernel number. Sci Rep. 2017;7:3788.

19. Jin H, Wen W, Liu J, Zhai S, Zhang Y, Yan J, Liu Z, Xia X, He Z. Genome-wide QTL mapping for wheat processing quality parameters in a Gaocheng 8901/Zhoumai 16 recombinant inbred line population. Front Plant Sci. 2016;7:1032.

20. Hoagland DR, Arnon DI. The water culture method for growing plants without soil. Calif Agric Exp Stn Bull. 1938;347:36-39.

21. Li F, Xiao Y, Jing S, Xia X, Chen X, Wang H, He Z. Genetic analysis of nitrogen and phosphorus utilization efficiency related traits at seedling stage of Jing 411 and its derivatives. J Triticeae Crops. 2015;35:737746.

22. Pound MP, French AP, Atkinson J, Wells DM, Bennett MJ, Pridmore TP. RootNav: Navigating images of complex root architectures. Plant Physiol. 2013;162:1802-1814.

23. Wang JP. Genetic analysis and functional marker development of key traits in wheat. Dissertation, Shandong Agricultural University, 2017..

24. Meng L, Li H, Zhang L, Wang J. QTL IciMapping: Integrated software for genetic linkage map construction and quantitative trait locus mapping in biparental populations. Crop J. 2015;3:269-283.

25. Kosambi DD. The estimation of map distances from recombination values. Annu Eugen. 1944;12:172-175.

26. Churchill GA, Doerge RW. Empirical threshold values for quantitative trait mapping. Genetics. 1994;138:963971.

27. Li H, Bradbury P, Ersoz E, Buckler ES, Wang J. Joint QTL linkage mapping for multiple-cross mating design sharing one common parent. PLoS One. 2011;6:e17573.

28. Sehgal D, Skot L, Singh R, Srivastava RK, Das SP, Taunk J, Sharma PC, Pal R, Raj B, Hash CT, Yadav RS. Exploring potential of pearl millet germplasm association panel for association mapping of drought tolerance traits. PLoS One. 2015;10:e0122165. 
29. R Core Team. R: A language and environment for statistical computing. R Foundation for Statistical Computing, Vienna, Austria. 2013.

30. Ren Y, Qian Y, Xu Y, Zou C, Liu D, Zhao X, Zhang A, Tong Y. Characterization of QTL for root traits of wheat grown under different nitrogen and phosphorus supply levels. Front Plant Sci. 2017;8:2096.

31. Xie Q, Fernando KM, Mayes S, Sparkes DL. Identifying seedling root architectural traits associated with yield and yield components in wheat. Ann Bot. 2017;119:1115-1129.

32. Ao J, Fu J, Tian J, Yan X, Liao H. Genetic variability for root morpho-architecture traits and root growth dynamics as related to phosphorus efficiency in soybean. Funct Plant Biol. 2010;37:304-312.

33. Bayuelo-Jiménez JS, Gallardo-Valdéz M, Pérez-Decelis VA, Magdaleno-Armas L, Ochoa I, Lynch JP. Genotypic variances for root traits of maize (Zea mays L.) from the Purhepecha Plateau under contrasting phosphorus availability. Field Crops Res. 2011;121:350-362.

34. Gu R, Chen F, Long L, Cai H, Liu Z, Yang J, Wang L, Li H, Li J, Liu W, Mi G, Zhang F, Yuan L. Enhancing phosphorus uptake efficiency through QTL-based selection for root system architecture in maize. J Genet Genomics. 2016;43:663-672.

35. Yang M, Hassan MA, Xu K, Zheng C, Rasheed A, Zhang Y, Jin X, Xia X, Xiao Y, He Z. Assessment of water and nitrogen use efficiencies through UAV-based multispectral phenotyping in winter Wheat. Front Plant Sci. 2020, 11. 0927.

36. Yang M, Wang C, Hassan M A, Wu Y, Xia X, Shi S, Xiao Y, He Z. QTL mapping of seedling biomass and root traits under different nitrogen conditions in bread wheat (Triticum aestivum L.). J. Integrat. Agric. 2020, 19, 2-14.

37. Su JY, Zheng Q, Li HW, Li B, Jing RL, Tong YP, Li ZS. Detection of QTL for phosphorus use efficiency in relation to agronomic performance of wheat grown under phosphorus sufficient and limited conditions. Plant Sci. 2009;176:824-836.

38. Sun JJ, Guo Y, Zhang GZ, Gao MG, Zhang GH, Kong FM, Zhao Y, Li SS. QTL mapping for seedling traits under different nitrogen forms in wheat. Euphytica. 2013;191:317-331.

39. Wojciechowski T, Gooding MJ, Ramsay L, Gregory PJ. The effects of dwarfing genes on seedling root growth of wheat. J Exp Bot. 2009;60:2565-2573.

40. Bai C, Liang Y, Hawkesford MJ. Identification of QTL associated with seedling root traits and their correlation with plant height in wheat. J Exp Bot. 2013;64:1745-1753

41. Narayanan S, Vara Prasad PV. Characterization of a spring wheat association mapping panel for root traits. Agron J. 2014;106:1593-1604.

42. Zhang H, Chen J, Li R, Deng Z, Zhang K, Liu B, Tian J. Conditional QTL mapping of three yield components in common wheat (Triticum aestivum L.). Crop J. 2016;4:220-228.

43. Shu K, Yang W. E3 Ubiquitin Ligases: ubiquitous actors in plant development and abiotic stress responses. Plant \& Cell Physiol. 2017, 58, 1461-1476.

44. Giri J. Glycinebetaine and abiotic stress tolerance in plants. Plant Signaling \& Behavior. 2011, 6, $1746-1751$.

45. Deng Y, Srivastava R, Howell SH. Protein kinase and ribonuclease domains of IRE1 confer stress tolerance, vegetative growth, and reproductive development in "Arabidopsis". Proceed National Academy of Sciences. 2013, 110, 19633-19638. 
46. Cui F, Ding A, Li J, Zhao C, Li X, Feng D, Wang X, Wang L, Gao J, Wang H. Wheat kernel dimensions: how do they contribute to kernel weight at an individual QTL level? J Genet. 2011;90:409-425.

47. Quarrie SA, Pekic Quarrie S, Radosevic R, Rancic D, Kaminska A, Barnes JD, Leverington M, Ceoloni C, Dodig D. Dissecting a wheat QTL for yield present in a range of environments: from the QTL to candidate genes. J Exp Bot. 2006;57:2627-2637.

48. Crossa J, Burgueño J, Dreisigacker S, Vargas M, Herrera-Foessel SA, Lillemo M, Singh RP, Trethowan R, Warburton M, Franco J, Reynolds M, Crouch JH, Ortiz R. Association analysis of historical bread wheat germplasm using additive genetic covariance of relatives and population structure. Genetics. 2007;177:1889-1913.

49. Kong FM, Guo Y, Liang X, Wu CH, Wang YY, Zhao Y, Li SS. Potassium (K) effects and QTL mapping for $\mathrm{K}$ efficiency traits at seedling and adult stages in wheat. Plant Soil. 2013;373:877-892.

50. Zhao Y, Li XY, Zhang SH, Wang J, Yang XF, Tian JC, Hai Y, Yang XJ. Mapping QTL for potassium-deficiency tolerance at the seedling stage in wheat (Triticum aestivum L.). Euphytica. 2014;198:185-198.

51. Gong X, Wheeler R, Bovill WD, McDonald GK. QTL mapping of grain yield and phosphorus efficiency in barley in a Mediterranean-like environment. Theor Appl Genet. 2016;129:1657-1672.

\section{Tables}

Table 1. Nutrient solution ingredients for wheat seedling growth.

\begin{tabular}{|llll|}
\hline Ingredient & Concentration (mmol/L) & Ingredient & Concentration (mmol/L) \\
\hline $\mathrm{K}_{2} \mathrm{SO}_{4}$ & 0.75 & $\mathrm{MnSO}_{4} \cdot \mathrm{H}_{2} \mathrm{O}$ & 0.001 \\
\hline $\mathrm{Ca}\left(\mathrm{NO}_{3}\right)_{2} \cdot 4 \mathrm{H}_{2} \mathrm{O}$ & 0.25 & $\mathrm{ZnSO}_{4} \cdot 7 \mathrm{H}_{2} \mathrm{O}$ & 0.001 \\
\hline $\mathrm{MgSO}_{4}$ & 0.60 & $\mathrm{CuSO}_{4} \cdot 5 \mathrm{H}_{2} \mathrm{O}$ & 0.0001 \\
\hline $\mathrm{FeEDTA}$ & 0.04 & $\mathrm{Na}_{2} \mathrm{MoO}_{4} \cdot 2 \mathrm{H}_{2} \mathrm{O}$ & 0.000005 \\
\hline $\mathrm{H}_{3} \mathrm{BO}_{3}$ & 0.001 & $\mathrm{KH}_{2} \mathrm{PO}_{4}$ & $0 / 0.005 / 0.25$ \\
\hline & & $\mathrm{KCl}$ & $0.35 / 0.345 / 0.10$ \\
\hline
\end{tabular}

Table 2. Phenotypic variances for three $\mathrm{P}$ treatments in $\mathrm{DH}$ lines 


\begin{tabular}{|c|c|c|c|c|c|c|c|c|}
\hline \multirow[t]{2}{*}{ Trait } & \multirow[t]{2}{*}{ P Level } & \multirow[t]{2}{*}{ Min } & \multirow[t]{2}{*}{ Max } & \multirow[t]{2}{*}{ Mean $\pm S D$} & \multirow[t]{2}{*}{$h^{2}$} & \multirow{2}{*}{$\begin{array}{l}\text { G } \\
\text { F.value }\end{array}$} & \multirow{2}{*}{$\begin{array}{l}\mathrm{T} \\
\text { F.value }\end{array}$} & \multirow{2}{*}{$\begin{array}{l}\text { GXT } \\
\text { F.value }\end{array}$} \\
\hline & & & & & & & & \\
\hline \multirow[t]{3}{*}{$\mathrm{RL}(\mathrm{cm})$} & C & 18.13 & 56.86 & $33.07 \pm 10.72$ & 0.90 & $2.89 * \star$ & \multirow[t]{3}{*}{$706.75^{\star \star}$} & \multirow[t]{3}{*}{$1.39 * *$} \\
\hline & $\mathrm{L}$ & 22.21 & 98.83 & $60.51 \pm 21.07$ & 0.83 & $1.53^{\star \star}$ & & \\
\hline & $\mathrm{H}$ & 2.01 & 63.37 & $40.00 \pm 12$ & 0.77 & 1.09 & & \\
\hline \multirow[t]{3}{*}{$\mathrm{RV}\left(\mathrm{cm}^{3}\right)$} & C & 0.05 & 0.23 & $0.11 \pm 0.03$ & 0.86 & $2.06 * \star$ & \multirow[t]{3}{*}{1252.17 ** } & \multirow[t]{3}{*}{$1.46^{\star \star}$} \\
\hline & $\mathrm{L}$ & 0.04 & 0.34 & $0.17 \pm 0.05$ & 0.81 & $1.45^{\star \star}$ & & \\
\hline & $\mathrm{H}$ & 0.08 & 0.42 & $0.22 \pm 0.008$ & 0.87 & $2.28 * \star$ & & \\
\hline \multirow[t]{3}{*}{$\mathrm{RD}\left(\mathrm{cm}^{3}\right)$} & C & 0.16 & 0.35 & $0.21 \pm 0.03$ & 0.87 & $2.27 \star \star$ & \multirow[t]{3}{*}{2274.54 ** } & \multirow[t]{3}{*}{$1.43^{* *}$} \\
\hline & $\mathrm{L}$ & 0.14 & 0.28 & $0.19 \pm 0.02$ & 0.86 & $2.01 * \star$ & & \\
\hline & $\mathrm{H}$ & 0.08 & 0.42 & $0.23 \pm 0.06$ & 0.88 & $2.54^{\star \star}$ & & \\
\hline \multirow[t]{3}{*}{ RTN } & $\mathrm{C}$ & 209 & 1822 & $716.25 \pm 246.7$ & 0.91 & $3.19 * \star$ & \multirow[t]{3}{*}{$403.58 * \star$} & \multirow[t]{3}{*}{$1.34^{\star \star}$} \\
\hline & $\mathrm{L}$ & 183 & 2477 & $1090.1 \pm 352.41$ & 0.84 & $1.76^{\star \star}$ & & \\
\hline & $\mathrm{H}$ & 184 & 1593 & $836.63 \pm 341.52$ & 0.82 & $1.56^{\star \star}$ & & \\
\hline \multirow[t]{3}{*}{$\operatorname{ROSA}\left(\mathrm{cm}^{3}\right)$} & C & 7.25 & 39.36 & $21.44 \pm 5.24$ & 0.88 & $2.45^{\star \star}$ & \multirow[t]{3}{*}{$700.51^{\star \star}$} & \multirow[t]{3}{*}{$1.36^{\star *}$} \\
\hline & $\mathrm{L}$ & 7.48 & 66.38 & $36.07 \pm 10.12$ & 0.82 & $1.48 * \star$ & & \\
\hline & $\mathrm{H}$ & 9.78 & 66.83 & $33.99 \pm 9.32$ & 0.83 & $1.68 * \star$ & & \\
\hline \multirow[t]{3}{*}{ SDW (mg) } & C & 0.02 & 2.06 & $0.04 \pm 0.009$ & 0.76 & 1.04 & \multirow[t]{3}{*}{$46.72^{\star \star}$} & \multirow[t]{3}{*}{1.01} \\
\hline & $\mathrm{L}$ & 0.02 & 0.09 & $0.05 \pm 0.01$ & 0.86 & $2.09 * \star$ & & \\
\hline & $\mathrm{H}$ & 0.005 & 0.12 & $0.071 \pm 0.009$ & 0.88 & $2.54^{\star \star}$ & & \\
\hline \multirow[t]{3}{*}{ RDW (mg) } & C & 0.01 & 0.03 & $0.02 \pm 0.001$ & 0.89 & $2.69 \star \star$ & \multirow[t]{3}{*}{$451.45^{\star \star}$} & \multirow[t]{3}{*}{1.41 ** } \\
\hline & $\mathrm{L}$ & 0.01 & 0.04 & $0.02 \pm 0.001$ & 0.84 & $1.72^{\star \star}$ & & \\
\hline & $\mathrm{H}$ & 0.01 & 0.12 & $0.07 \pm 0.02$ & 0.89 & $2.67 * \star$ & & \\
\hline TDW (mg) & C & 0.01 & 2.08 & $0.06 \pm 0.008$ & 0.76 & 1.05 & $65.22^{\star \star}$ & 1.03 \\
\hline & $\mathrm{L}$ & 0.01 & 0.12 & $0.07 \pm 0.02$ & 0.85 & $1.88 * \star$ & & \\
\hline & $\mathrm{H}$ & 0.01 & 0.04 & $0.02 \pm 0.001$ & 0.88 & $2.42^{\star \star}$ & & \\
\hline RRS & C & 0.01 & 0.71 & $0.38 \pm 0.07$ & 0.91 & $3.34^{\star \star}$ & $180.38 * \star$ & 1.03 \\
\hline & $\mathrm{L}$ & 0.18 & 1.04 & $0.39 \pm 0.07$ & 0.83 & $1.68 * \star$ & & \\
\hline & $\mathrm{H}$ & 0.01 & 0.16 & $0.09 \pm 0.02$ & 0.88 & $2.50 * \star$ & & \\
\hline
\end{tabular}

* Significant at $P<0.05$, ** at $P<0.001$ and *** at $P<0.0001$ 
Abbreviations: $\mathrm{C}$, zero control; $\mathrm{L}$, low $\mathrm{P}$ treatment; $\mathrm{H}$, high $\mathrm{P}$ treatment; $\mathrm{RL}$, root length; $\mathrm{RV}$, root volume; $\mathrm{RD}$, root diameter; RTN, root tip number; ROSA, root surface area; SDW, shoot dry weight; RDW, root dry weight; TDW, total dry weight; RRS, ratio of root to shoot dry weight

Table 3. QTLs for root system architecture and root biomass-related traits identified under three P treatments 


\begin{tabular}{|c|c|c|c|c|c|c|c|c|}
\hline Trait & Treatment & $\mathrm{QTL}^{\mathrm{a}}$ & Marker interval & $\begin{array}{l}\text { Physical } \\
\text { interval } \\
(\mathrm{Mb})\end{array}$ & $\begin{array}{l}\text { Genetic } \\
\text { position } \\
\text { (cM) }\end{array}$ & LOD $^{d}$ & $\begin{array}{l}\text { PVE } \\
\text { (\%) }\end{array}$ & $\underset{f}{\text { Add }}$ \\
\hline \multirow[t]{8}{*}{ RL } & C & $\begin{array}{l}\text { QRL.caas- } \\
\text { 1BL }\end{array}$ & $\begin{array}{l}A X-10928674- \\
A X-94446430\end{array}$ & $\begin{array}{l}\text { 671.33- } \\
688.38\end{array}$ & 2.5 & 3.13 & 5.56 & -18.89 \\
\hline & & $\begin{array}{l}\text { QRL.caas- } \\
\text { 7AS.1 }\end{array}$ & $\begin{array}{l}A X-110432090 \\
-A X- \\
109345074\end{array}$ & $\begin{array}{l}20.95- \\
22.87\end{array}$ & 0.97 & 3.51 & 6.38 & 19.78 \\
\hline & & $\begin{array}{l}\text { QRL.caas- } \\
\text { GAL }\end{array}$ & $\begin{array}{l}A X-86165298- \\
A X-109431293\end{array}$ & $\begin{array}{l}612.11- \\
613.49\end{array}$ & 1.17 & 4.53 & 8.20 & 23.51 \\
\hline & & $\begin{array}{l}\text { QRL.caas- } \\
7 A L\end{array}$ & $\begin{array}{l}A X-109966788 \\
-A X-94819074\end{array}$ & $\begin{array}{l}725.54- \\
734.54\end{array}$ & 4.84 & 3.37 & 6.22 & 19.54 \\
\hline & L & $\begin{array}{l}\text { QRL.caas- } \\
6 B L\end{array}$ & $\begin{array}{l}A X-109368729 \\
-A X-95094583\end{array}$ & $\begin{array}{l}699.99- \\
711.76\end{array}$ & 4 & 4.90 & 8.61 & 45.43 \\
\hline & & $\begin{array}{l}\text { QRL.caas- } \\
7 B L\end{array}$ & $\begin{array}{l}A X-95025477- \\
A X-109289805\end{array}$ & $\begin{array}{l}700.83- \\
705.84\end{array}$ & 2.35 & 3.74 & 6.57 & -38.04 \\
\hline & & $\begin{array}{l}\text { QRL.caas- } \\
\text { 7AL }\end{array}$ & $\begin{array}{r}A X-109966788 \\
-A X-94819074\end{array}$ & $\begin{array}{l}\text { 725.54- } \\
734.54\end{array}$ & 4.84 & 3.46 & 5.50 & 35.19 \\
\hline & $\mathrm{H}$ & $\begin{array}{l}\text { QRL.caas- } \\
7 A S .2\end{array}$ & $\begin{array}{l}A X-109955164 \\
-A X- \\
109445593\end{array}$ & $\begin{array}{l}116.62- \\
122.18\end{array}$ & 1.72 & 4.72 & 11.89 & 30.81 \\
\hline \multirow[t]{3}{*}{ RV } & C & $\begin{array}{l}\text { QRV.caas- } \\
6 D S\end{array}$ & $\begin{array}{l}A X-10934618- \\
A X-94913665\end{array}$ & $\begin{array}{l}18.67- \\
25.66\end{array}$ & 3.45 & 3.98 & 8.41 & 0.01 \\
\hline & & $\begin{array}{l}\text { QRV.caas- } \\
4 B S\end{array}$ & $\begin{array}{l}A X-108815849 \\
-A X- \\
109491270\end{array}$ & $\begin{array}{l}21.48- \\
21.79\end{array}$ & 2.5 & 4.90 & 10.32 & 0.01 \\
\hline & $\mathrm{H}$ & $\begin{array}{l}\text { QRV.caas- } \\
\text { 7AS }\end{array}$ & $\begin{array}{l}A X-108763612 \\
-A X- \\
111263013\end{array}$ & $\begin{array}{l}85.44- \\
85.71\end{array}$ & 1.95 & 3.49 & 8.82 & 0.01 \\
\hline \multirow[t]{7}{*}{ RTN } & L & $\begin{array}{l}\text { QRTN.caas- } \\
6 B L\end{array}$ & $\begin{array}{l}A X-109368729 \\
-A X-95094583\end{array}$ & $\begin{array}{l}699.99- \\
711.76\end{array}$ & 4 & 4.21 & 7.08 & 73.56 \\
\hline & & $\begin{array}{l}\text { QRTN.caas- } \\
2 B L\end{array}$ & $\begin{array}{l}A X-86176885- \\
A X-94933613\end{array}$ & $\begin{array}{l}647.32- \\
647.71\end{array}$ & 0.35 & 2.86 & 4.79 & 57.39 \\
\hline & & $\begin{array}{l}\text { QRTN.caas- } \\
7 B L\end{array}$ & $\begin{array}{l}A X-95025477- \\
A X-109289805\end{array}$ & $\begin{array}{l}700.83- \\
705.84\end{array}$ & 2.35 & 5.52 & 9.78 & -81.68 \\
\hline & & $\begin{array}{l}\text { QRTN.caas- } \\
7 A L\end{array}$ & $\begin{array}{l}A X-109966788 \\
-A X-94819074\end{array}$ & $\begin{array}{l}725.54- \\
734.54\end{array}$ & 4.84 & 2.77 & 4.64 & 56.97 \\
\hline & $\mathrm{H}$ & $\begin{array}{l}\text { QRTN.caas- } \\
2 D L\end{array}$ & $\begin{array}{l}A X-94959623- \\
A X-94821426\end{array}$ & $\begin{array}{l}79.54- \\
82.22\end{array}$ & 1.26 & 2.74 & 7.78 & 45.97 \\
\hline & & $\begin{array}{l}\text { QRTN.caas- } \\
\text { 7AS }\end{array}$ & $\begin{array}{l}A X-109955164 \\
-A X- \\
109445593\end{array}$ & $\begin{array}{l}116.62- \\
122.18\end{array}$ & 1.72 & 3.84 & 8.17 & 48.20 \\
\hline & & $\begin{array}{l}\text { QRTN.caas- } \\
3 D L\end{array}$ & $\begin{array}{l}A X-110036411 \\
-A X-\end{array}$ & $\begin{array}{l}559.77- \\
566.72\end{array}$ & 2.79 & 2.99 & 6.21 & 42.26 \\
\hline
\end{tabular}


109917936

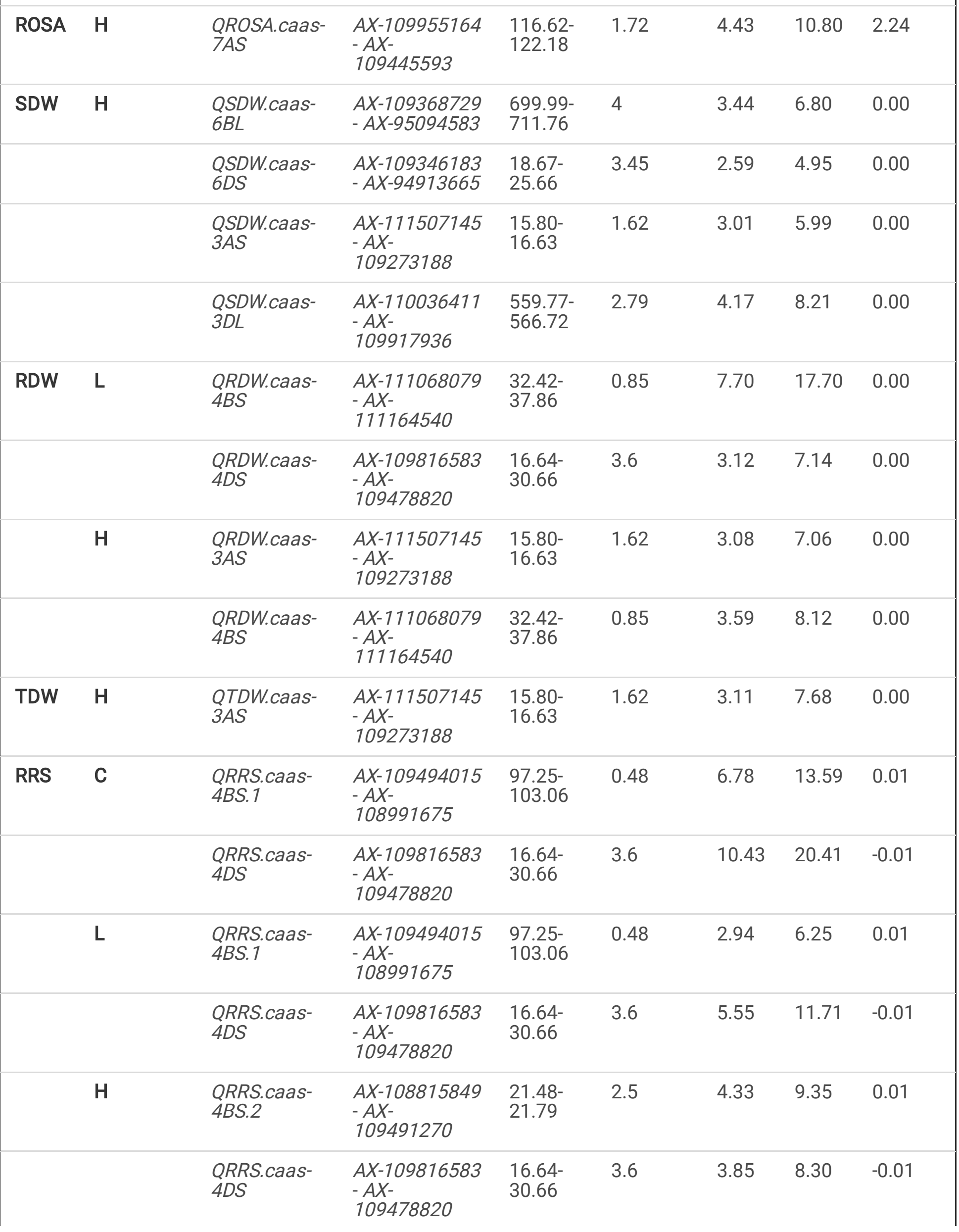


a Quantitative trait loci

b Physical positions of SNP markers based on wheat genome sequences from the International Wheat Genome Sequencing Consortium (IWGSC, http://www.wheatgenome.org/)

${ }^{\mathrm{c}}$ Genetic position of closest marker to the identified QTL on linkage map

d LOD value of each QTL

e Phenotypic variance explained by QTL

${ }^{f}$ A positive sign means the increased effect contributed by Zhongmai 895, whereas the negative effect was contributed by Yangmai 16

Abbreviations: C, control; L, low P treatment; $H$, high P treatment; RL, root length; RV, root volume; RD, root diameter; RTN, root tip number; ROSA, root surface area; SDW, shoot dry weight; RDW, root dry weight; TDW, total dry weight; RRS, ratio of root to shoot dry weight.

$(\mathrm{Q}=\mathrm{QTL})+($ caas= Chinese Academy of Agricultural Sciences $)+$ Chromosome=long arm (L) or short arm (S)

Table 4. Joint QTL analysis results for pleiotropic QTL in clusters 


\begin{tabular}{|c|c|c|c|c|c|c|c|}
\hline Cluster & Trait & $\begin{array}{l}\mathrm{P} \\
\text { Level }\end{array}$ & Chromosome & Marker interval & $\begin{array}{l}\text { Physical } \\
\text { interval }^{\text {a }}(\mathrm{Mb})\end{array}$ & $\operatorname{Pr}(>|t|)^{b}$ & $\begin{array}{l}\text { Adjusted } \\
\mathrm{R}^{2}\end{array}$ \\
\hline \multirow[t]{2}{*}{ C1 } & SDW & $\mathrm{H}$ & $3 \mathrm{D}$ & $\begin{array}{l}A X-110036411-A X- \\
109917936\end{array}$ & 559.77-566.72 & $0.02^{\star}$ & 0.38 \\
\hline & RTN & $\mathrm{H}$ & & & & & \\
\hline \multirow[t]{2}{*}{$\mathrm{C} 2$} & $\mathrm{RV}$ & C & 4B & $\begin{array}{l}A X-109491270-A X- \\
108815849\end{array}$ & $21.48-21.79$ & $0.05^{\star}$ & 0.12 \\
\hline & RRS & $\mathrm{H}$ & & & & & \\
\hline \multirow[t]{2}{*}{ C3 } & RDW & L & $4 \mathrm{D}$ & $\begin{array}{l}A X-109816583-A X- \\
109478820\end{array}$ & $16.64-30.66$ & $\begin{array}{l}0.15 \\
0.18\end{array}$ & $\begin{array}{l}0.18 \\
0.12\end{array}$ \\
\hline & RRS & $C, L$ & & & & & \\
\hline \multirow[t]{2}{*}{ C4 } & $\mathrm{RL}$ & L & $6 B$ & $\begin{array}{l}A X-94471535-A X- \\
95094583\end{array}$ & 704.88-711.76 & 0.7 & 0.75 \\
\hline & RTN & L & & & & & \\
\hline \multirow[t]{3}{*}{ C5 } & $\mathrm{RL}$ & $\mathrm{H}$ & $7 A$ & $\begin{array}{l}A X-109955164-A X- \\
109445593\end{array}$ & $116.62-122.18$ & $\begin{array}{l}0.68, \\
0.55 \\
0.71\end{array}$ & $\begin{array}{l}0.76 \\
0.90 \\
0.74\end{array}$ \\
\hline & RTN & $\mathrm{H}$ & & & & & \\
\hline & ROSA & $\mathrm{H}$ & & & & & \\
\hline \multirow[t]{2}{*}{$\mathrm{C} 6$} & $\mathrm{RL}$ & $\mathrm{H}$ & $7 A$ & $\begin{array}{l}A X-109966788-A X- \\
94819074\end{array}$ & 725.54-134.54 & $0.037^{\star}$ & 0.12 \\
\hline & RTN & L & & & & & \\
\hline \multirow[t]{2}{*}{$\mathrm{C7}$} & $\mathrm{RL}$ & L & $7 \mathrm{~B}$ & $\begin{array}{l}A X-109289805-A X- \\
95025477\end{array}$ & $700.83-705.84$ & 0.8 & 0.75 \\
\hline & RTN & L & & & & & \\
\hline
\end{tabular}

a Physical positions of SNP markers based on wheat genome sequences from the International Wheat Genome Sequencing Consortium (IWGSC, http://www.wheatgenome.org/)

b Significance of t-values at $P<0.05$

Abbreviations: $\mathrm{C}$, control; $\mathrm{L}$, low $\mathrm{P}$ treatment; $\mathrm{H}$, high $\mathrm{P}$ treatment; $\mathrm{RL}$, root length; $\mathrm{RV}$, root volume; $\mathrm{RD}$, root diameter; RTN, root tip number; ROSA, root surface area; SDW, shoot dry weight; RDW, root dry weight; TDW, total dry weight; RRS, ratio of root to shoot dry weight. 
Table 5. QTL with corresponded candidate genes and putative proteins.

\begin{tabular}{|c|c|c|c|c|c|c|c|c|}
\hline \multirow{8}{*}{ BL. } & & Qmi: & Starker hasnal & Phovialiaten $x^{\prime}$ (ob) & Sey of SNP mertes & MhatGexs & Datasx fnneSNP & 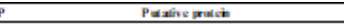 \\
\hline & & Qet_natr. $78 L$. & 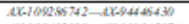 & $67.33-638.38$ & 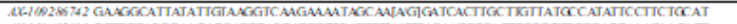 & TrescCSI BD2CA5 500 & $23 \mathrm{~W}$ & Rivelpepulán \\
\hline & & 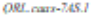 & 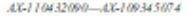 & $30.95-22.87$ & 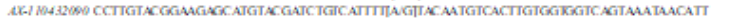 & Traces $A 0104610$ & $2 \mathrm{AKl}$ & Dosace roxitians \\
\hline & & Qer_cosisese. & 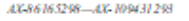 & $61211-61349$ & 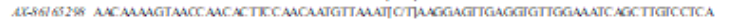 & 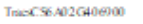 & $72 \mathrm{~b}$ & Bisapepulain \\
\hline & & Qef_casr.7as. & 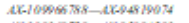 & $72554-73454$ & 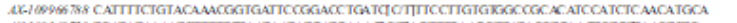 & Thascs & 2876 & Híupepoulan \\
\hline & & 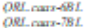 & 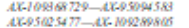 & $\begin{array}{l}0,02929-71176 \\
0083-70584\end{array}$ & 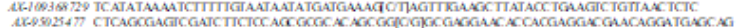 & 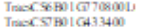 & ${ }_{724.8 \mathrm{~b}}^{28 \mathrm{~b}}$ & 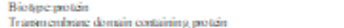 \\
\hline & & ger_nasr. 7 as. & A. & $72554-73454$ & 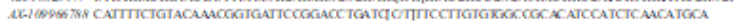 & Thine CS $A 01685700 \mathrm{U}$ & $287 \mathrm{k}$, & Bivapcipolish \\
\hline & & Qeer_nam-7as.2 & 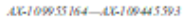 & $11662-122.18$ & 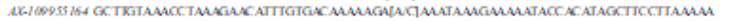 & 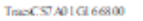 & $72 \mathrm{~b}$ & Sinile we Chpo \\
\hline \multirow[t]{3}{*}{ Rv } & c & OQV camatis & A. & $18.67-2566$ & 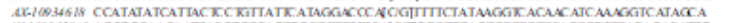 & 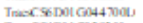 & $14 \mathrm{db}$ & Hivapepolis \\
\hline & & QRV Mara $-A R S$ & 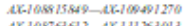 & $21.48-2179$ & 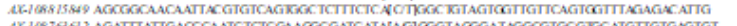 & 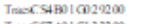 & $287 \mathrm{~W}$ & Hieqpepolin \\
\hline & & 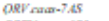 & 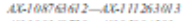 & $85.4-8531$ & 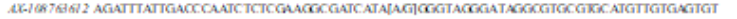 & 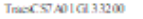 & $2.17 \mathrm{k}$ & Hiobepepuliait \\
\hline \multirow[t]{4}{*}{ RTV } & L. & 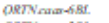 & 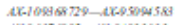 & $0292-71176$ & 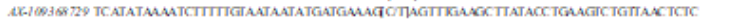 & 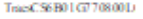 & 284.8sb & Biselpepoulin \\
\hline & & 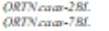 & 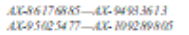 & $\begin{array}{l}64732-64731 \\
0083-70584\end{array}$ & 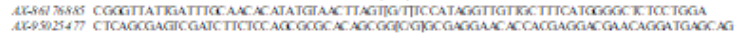 & 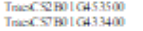 & $72 b$ & 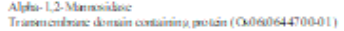 \\
\hline & & 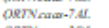 & 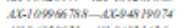 & $72554-73454$ & 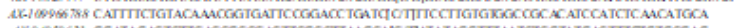 & 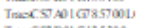 & $287 \mathrm{~W}$ & Hiequepoudin \\
\hline & & 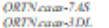 & 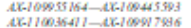 & $\begin{array}{l}11662,-12218 \\
55277-56772\end{array}$ & 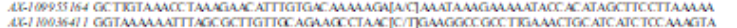 & 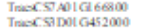 & 2314, & 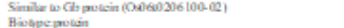 \\
\hline & & 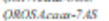 & 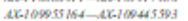 & $11662-122.18$ & 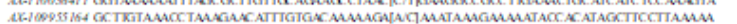 & 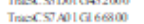 & $72 \mathrm{~b}$ & 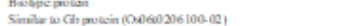 \\
\hline \multirow{4}{*}{ siow } & & QSDW. mas $\rightarrow$ ABS. & 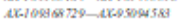 & e2292-711.76 & 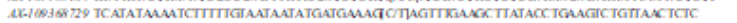 & 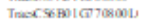 & $23.6 \mathrm{~s}$ & Bivapepouling \\
\hline & & asDitramanas & 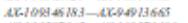 & $18.67-2566$ & & 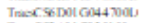 & 14 & Binapepoulin \\
\hline & & asDiviours its & 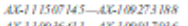 & $15.80-16.63$ & 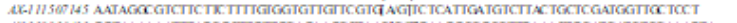 & 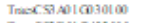 & 14kb & 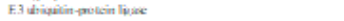 \\
\hline & & 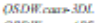 & 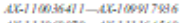 & $55277-56672$ & 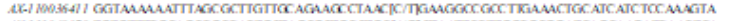 & 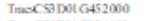 & 28436 & Bistapepoulain \\
\hline \multirow[t]{3}{*}{ RePW } & L. & 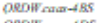 & 9-20.7n 164540 & 32.42 & semas & Thased & 7L.7W & Howstatioul peed \\
\hline & & 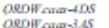 & 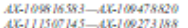 & $\begin{array}{l}16.64 .30 .66 \\
15.80-1669\end{array}$ & 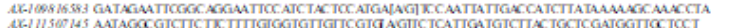 & 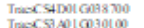 & $\begin{array}{lll}1.1406 \\
1400\end{array}$ & 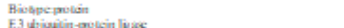 \\
\hline & & 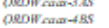 & 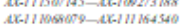 & $32.42-3786$ & 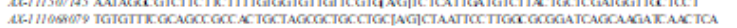 & 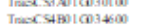 & $7 \mathrm{LT}, \mathrm{W}$, & 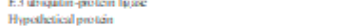 \\
\hline TIN & н & 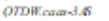 & 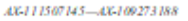 & $15.90-16.63$ & 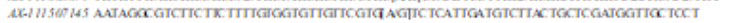 & Trascs:Aotcoset 0 & 14kb & 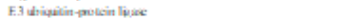 \\
\hline \multirow[t]{4}{*}{ RIS } & & 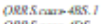 & 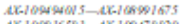 & n.25-10306 & 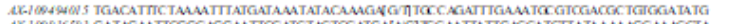 & Thas SAB 109400 & $72 \mathrm{~b}$ & Bäbipepulien \\
\hline & & 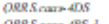 & 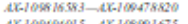 & $16.64-3066$ & 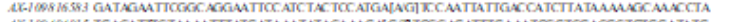 & 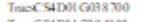 & 1.140, & Bivepepalain \\
\hline & L. & 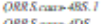 & 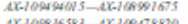 & $97.25-10306$ & 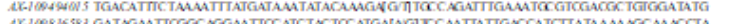 & 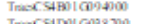 & $726 \mathrm{~b}$ & Biequepousin \\
\hline & & aerscamas & C. & $16.64-3066$ & 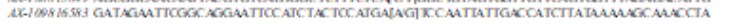 & 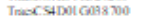 & 1.146 & \\
\hline
\end{tabular}

${ }^{a}$ Quantitative trait loci

${ }^{b}$ Physical positions of SNP markers based on wheat genome sequences from the International Wheat Genome Sequencing Consortium (IWGSC, http://www.wheatgenome.org/).

Abbreviations: $\mathrm{C}$, control; L, low P treatment; $\mathrm{H}$, high P treatment; RL, Root length; RV, Root volume; RD, Root diameter; RTN, root tip number; ROSA, root surface area; SDW, shoot dry weight; RDW, root dry weight; TDW, total dry weight; RRS, ratio of root to shoot dry weight.

\section{Figures}



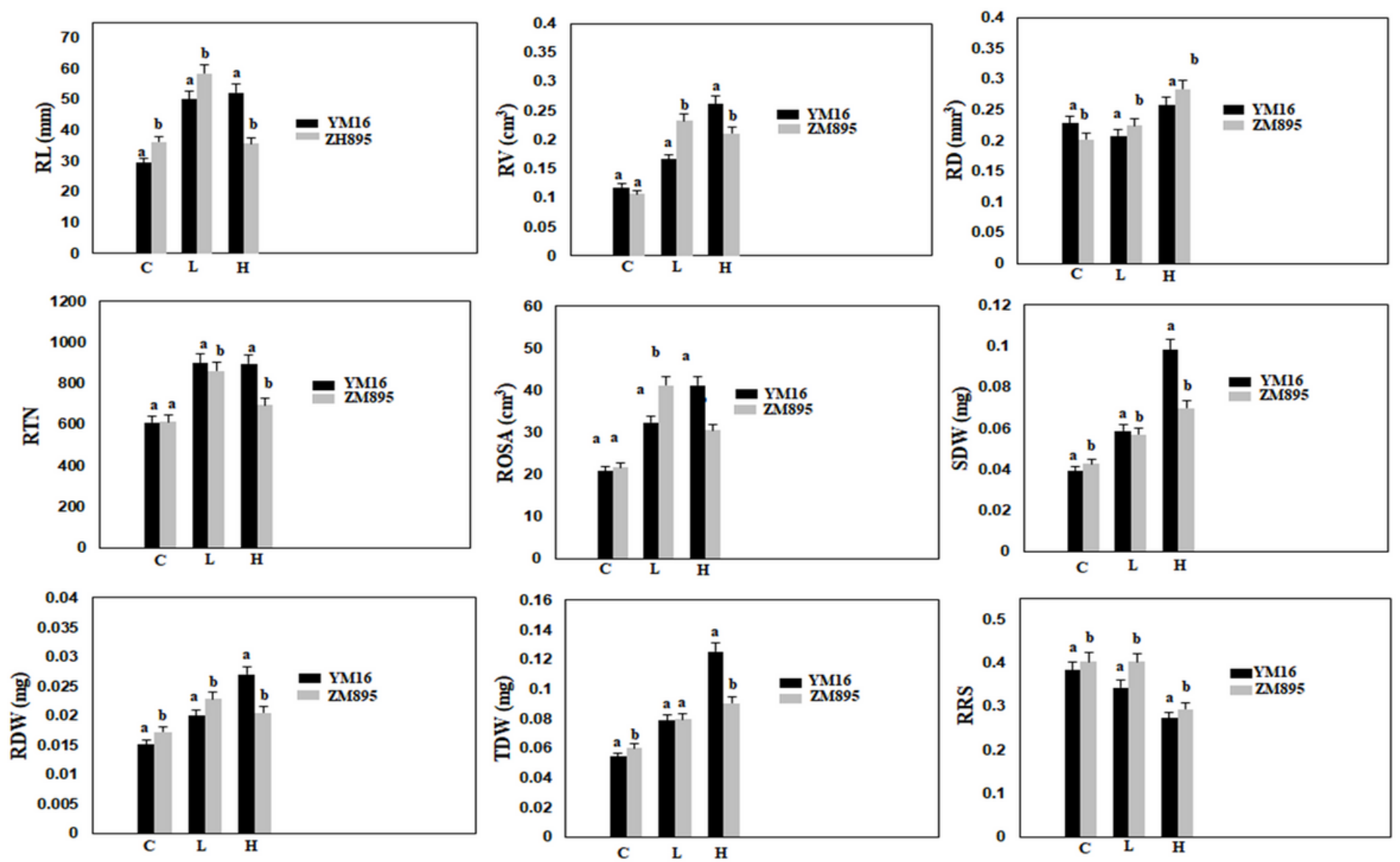

\section{Figure 1}

The phenotypic difference between parents Yangmai 16 and Zhongmai 895 under $P$ treatments. Error bars represent standards deviation for each proportion; letters indicate significant differences between the genotypes determined by Duncan tests Abbreviations: ZM895, Zhongmai 895; YM16, Yangmai 16; C, control; L, low P treatment; $H$, high $P$ treatment; $R L$, root length; RV, root volume; RD, root diameter; RTN, root tip number; ROSA, root surface area; SDW, shoot dry weight; RDW, root dry weight; TDW, total dry weight; RRS, ratio of root to shoot dry weight. 


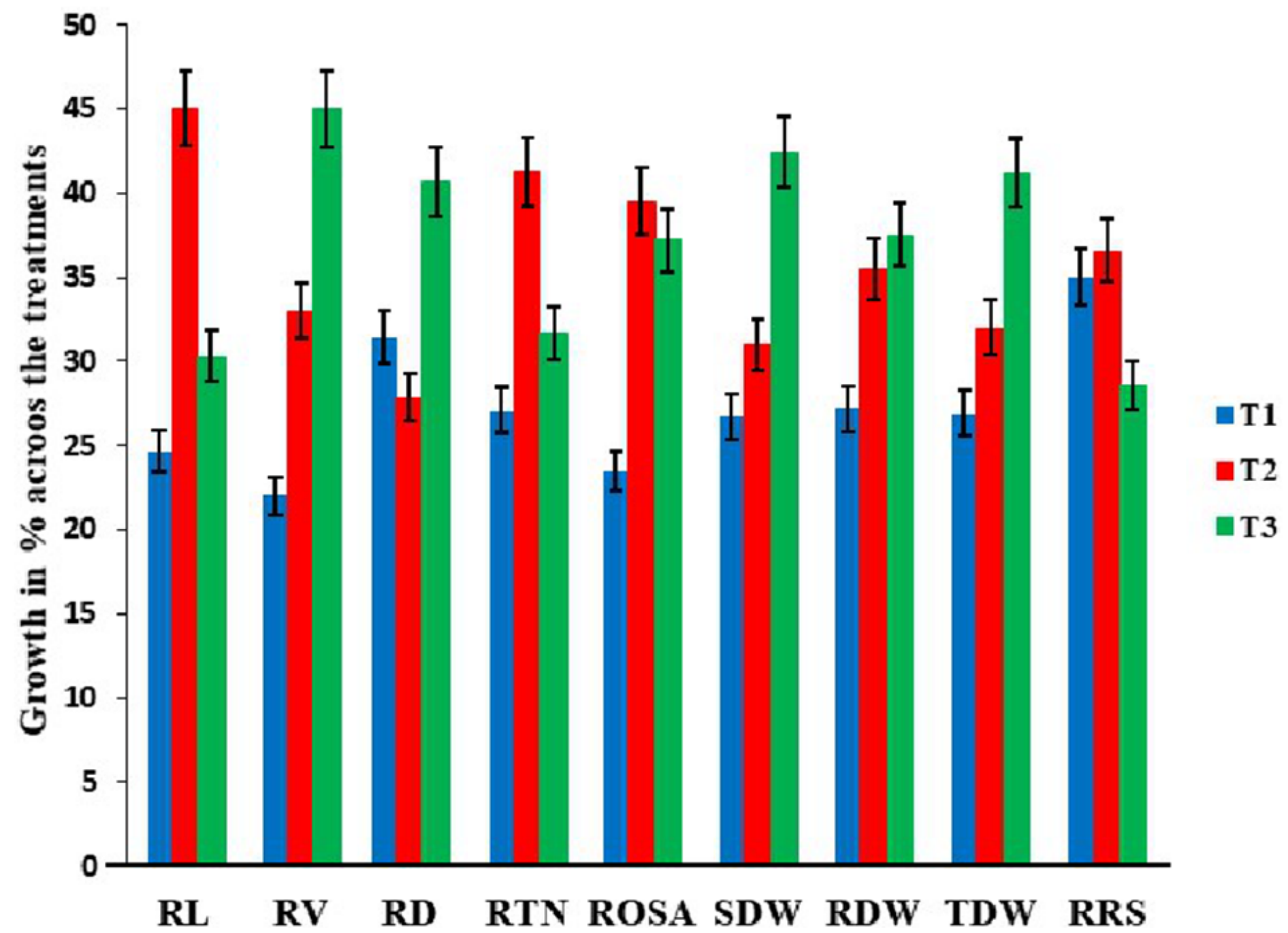

Figure 2

Effects of phosphorus treatment on traits in DH lines. Error bars represent standard deviation for each trait under $\mathrm{P}$ treatments. Abbreviations: $\mathrm{C}$, control; L, low P treatment; $\mathrm{H}$, high $\mathrm{P}$ treatment; $\mathrm{RL}$, root length; RV, root volume; RD, root diameter; RTN, root tip number; ROSA, root surface area; SDW, shoot dry weight; RDW, root dry weight; TDW, total dry weight; RRS, ratio of root to shoot dry weight 

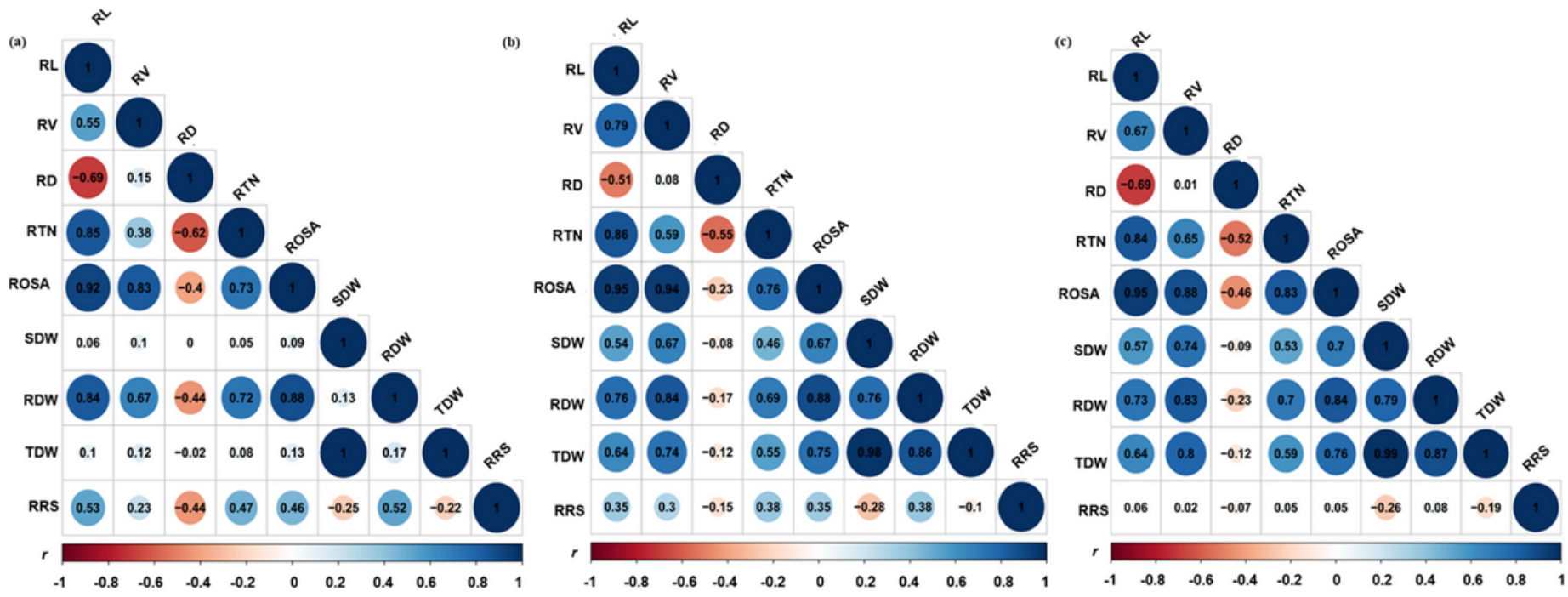

\section{Figure 3}

Correlation analysis among the traits under (a) control, (b) low and (c) high P treatment. Intensities of blue colour shows degrees of positive and red colour shows degrees of negative correlations; circle sizes indicate low to high significance Abbreviations: RL, root length; RV, root volume; RD, root diameter; RTN, root tip number; ROSA, root surface area; SDW, shoot dry weight; RDW, root dry weight; TDW, total dry weight; RRS, ratio of root to shoot dry weight 

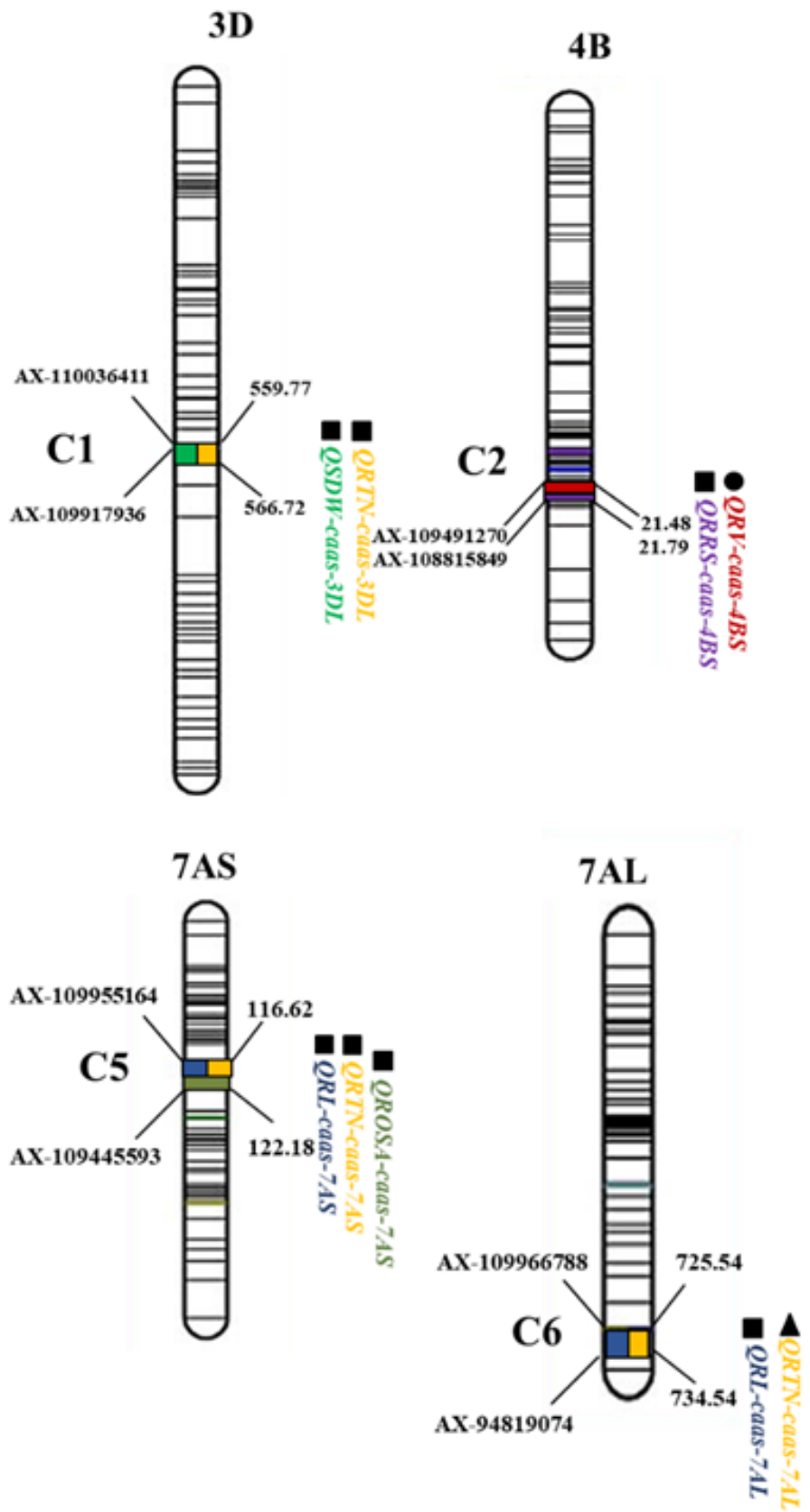
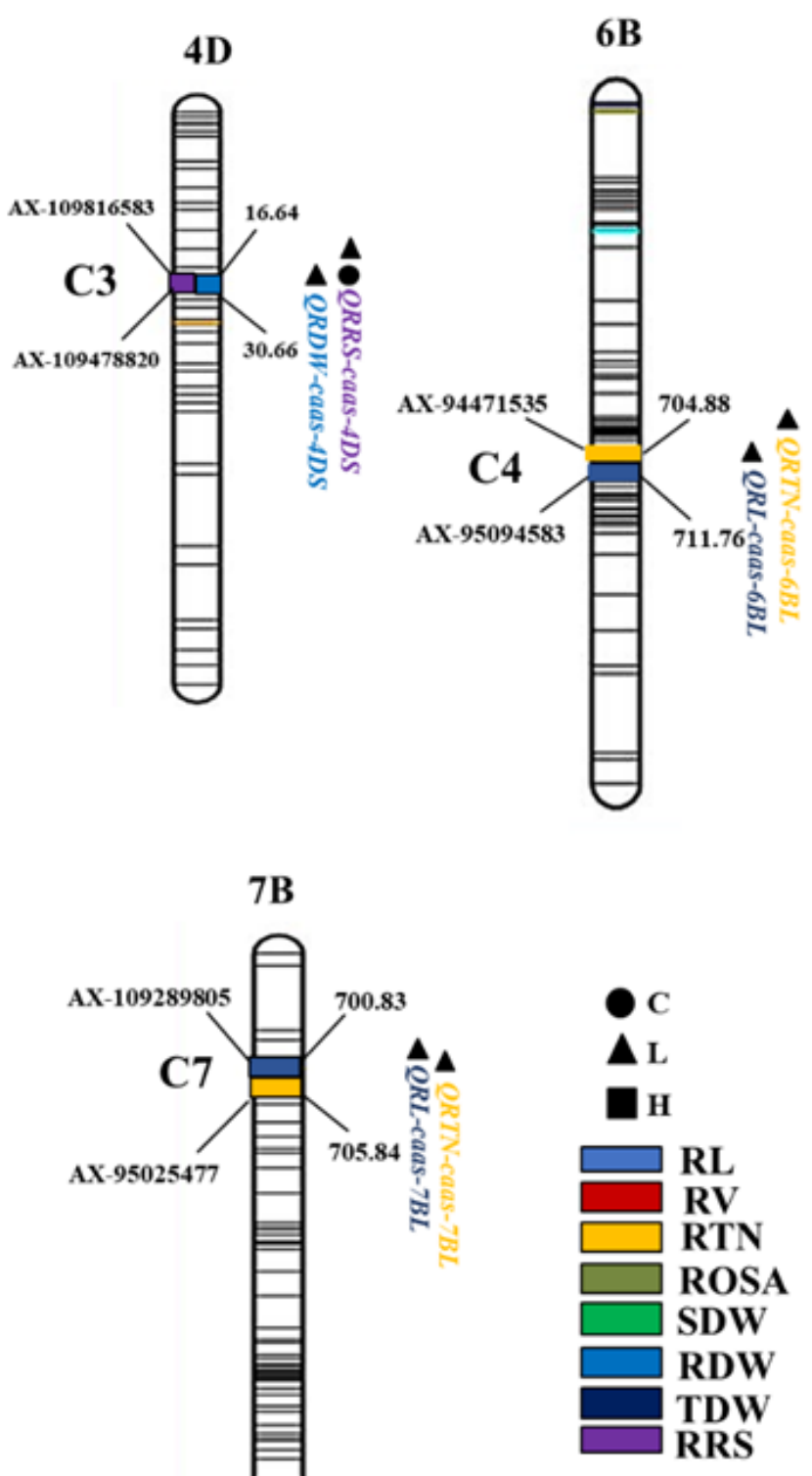

Figure 4

Seven QTL clusters containing pleiotropic loci with closely linked markers and physical positions. Abbreviations: C, control; L, low P treatment; $H$, high $P$ treatment; RL, root length; RV, root volume; RTN, root tip number; ROSA, root surface area; SDW, shoot dry weight; RDW, root dry weight; TDW, total dry weight; RRS, ratio of root to shoot dry weight.

\section{Supplementary Files}

This is a list of supplementary files associated with this preprint. Click to download. 
- SupplementaryFiles04122020.docx

Page 25/25 